\title{
Correction to: Evaluation of visual image for remotely controlled ship
}

\author{
Ai Hoshino ${ }^{1}$ - Ayako Umeda ${ }^{1} \cdot$ Takumi Nishina $^{1} \cdot$ Hidemasa Kimura $^{1} \cdot$ Katsuya Hakozaki $^{1} \cdot$ Tsuyoshi Ode $^{1}$. \\ Etsuro Shimizu ${ }^{1}$
}

Published online: 13 February 2020

(c) International Society of Artificial Life and Robotics (ISAROB) 2020

\section{Correction to: Artifcial Life and Robotics https://doi.org/10.1007/s10015-020-00584-9}

The article Evaluation of visual image for remotely controlled ship, written by Ai Hoshino, Ayako Umeda, Takumi Nishina, Hidemasa Kimura, Katsuya Hakozaki, Tsuyoshi Ode and Etsuro Shimizu, was originally published electronically on the publisher's internet portal (currently SpringerLink) on 27 January 2020 with open access. With the author(s)' decision to step back from Open Choice, the copyright of the article changed on 14 February 2020 to (C) International Society of Artificial Life and Robotics (ISAROB) 2020 and the article is forthwith distributed under the terms of copyright.

The original article was updated.

Publisher's Note Springer Nature remains neutral with regard to jurisdictional claims in published maps and institutional affiliations.

The original article can be found online at https://doi.org/10.1007/ s10015-020-00584-9.

$\triangle$ Ai Hoshino

m194020@edu.kaiyodai.ac.jp

1 Tokyo University of Marine Science and Technology, Tokyo, Japan 